\title{
Performance-related pay and labor productivity
} Do pay incentives and financial participation schemes have an effect on a firm's performance?

Keywords: performance-related pay, productivity, pay incentives, financial participation

\section{ELEVATOR PITCH}

Many firms offer employees a remuneration package that links pay to performance as a means of motivation. It also improves efficiency and reduces turnover and absenteeism. The effects on productivity depend on the type of scheme employed (individual or group performance) and its design (commissions, piece-rate or sharing schemes). Individual incentives demonstrate the largest effect, while group or team incentives are smaller in magnitude. The case for government intervention through tax breaks and other financial incentives is highly debated due to differences across firms and the potential for economic inefficiencies.

\section{KEY FINDINGS}

\section{Pros}

๑ Linking pay to performance increases workers' motivation, effort, and loyalty to the company.

๑ Incentive schemes work as a screening mechanism by encouraging only more productive workers to apply.

† Performance-related pay can improve macroeconomic performance and the resilience of employment to economic shocks.

๑ Incentive schemes support the allocation of highquality workers to high-productivity firms.

- Share-ownership schemes are associated with better firm performance in the longer-term.

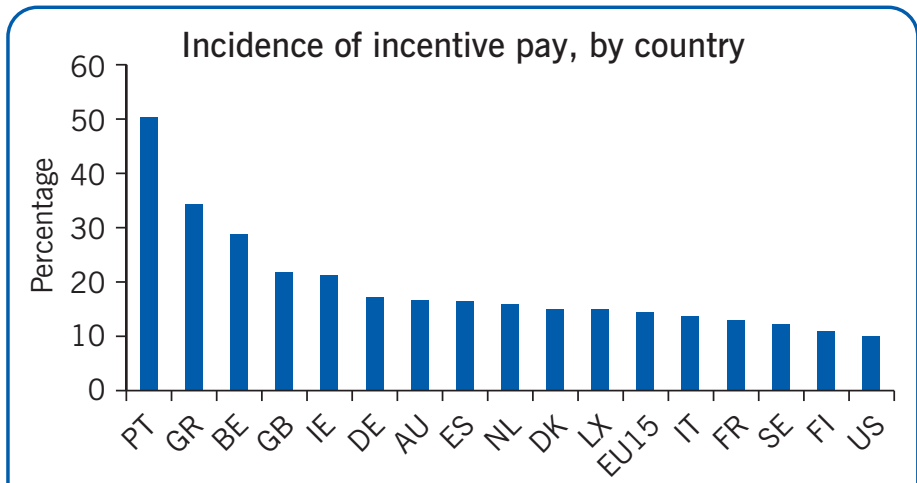

Source: Boeri, T., C. Lucifora, and K. J. Murphy. Executive Remuneration and Employee Performance-Related Pay. Oxford: Oxford University Press, 2013; p. 144; Figure 6.1.

\section{Cons}

- Risk-averse workers may prefer flat-rate schemes to performance-related pay.

- Explicit incentives may displace workers' intrinsic motivation.

- When rewards are paid for profits, but no penalty is incurred if losses are made, pay incentives may have perverse and counterproductive effects.

- Performance-related pay may generate excessive work intensification and psychological stress.

- Government intervention through tax breaks and financial incentives are not necessarily efficient.

\section{AUTHOR'S MAIN MESSAGE}

Performance-related pay (PRP) schemes increase firm productivity. Individual schemes are associated with large increases in productivity, while group incentives and profit-sharing exhibit smaller effects. Empirical evidence suggests that policy intervention that facilitates PRP can be successful in terms of productivity gain for some young and small firms. However, government intervention "across the board" should be cautious, as fiscal incentives may benefit firms that already have PRP schemes, or induce firms to introduce them simply to gain tax advantages, with resultant economic inefficiencies. 


\section{MOTIVATION}

Many firms offer employees a remuneration package that links pay to performance as a means of incentive and motivation. Indeed, remunerating workers "by the piece," or via a "piece rate," has been the norm for a very long time in the manufacturing industry. There are many different types of pay incentives, including individual performance pay, group performance pay, as well as financial participation (e.g. profit-sharing and employee stock ownership). Every employer is concerned about finding ways of improving the efficiency and productivity of workers in the firm. Providing an appropriate compensation package that combines a fixed-pay component with a variable-pay element, linked to a measure of a firm's performance, has proved to be a popular instrument for stimulating labor productivity within firms.

The variable part of compensation is often structured in different types of schemes: individual or group performance pay is provided when individual or team performance meets a given target. Alternatively, there are also financial participation schemes, which benefit the worker and are linked to a firm's profits, sales, share price, or other measures of performance. At the level of the firm, the effects of PRP on productivity are expected to work through different channels. First, PRP schemes are used to motivate workers and to elicit higher effort. Second, incentive schemes work as a screening mechanism when new workers are hired, as they encourage only the most productive workers to apply. Finally, pay incentives also increase the attachment, or loyalty, of incumbent workers to the firm, thereby reducing turnover and absenteeism. At a national level, policymakers also encourage the introduction of PRP schemes as a means of improving aggregate productivity, wage flexibility, and resilience of employment to economic shocks without putting pressure on wage levels.

Given this, it is necessarily important to know what the main effects of the introduction of different incentive pay schemes are on productivity, as well as on other economic outcomes.

\section{DISCUSSION OF PROS AND CONS}

PRP schemes, or performance incentives, have become more widespread in recent decades, both in Europe and the US [1]. This is partly explained by the spread of "high-involvement management" practices, in which workers are provided with more decision-making power, information, and, very often, incentive compensation schemes. It can also be explained by advances in information and communication technologies which, by reducing the costs of measuring employees' performance, make incentive schemes easier to implement.

When a firm introduces an incentive scheme it does so because it hopes to improve its performance, in terms of productivity, sales, and profits, etc. The effect on performance is the result of a "direct" effect of pay incentives on employees' effort and motivation, as well as an "indirect" effect on the composition of the workforce. The latter being a result of the "sorting" that occurs in new hires, whereby only the most productive workers will apply for the position.

An important question for both firms and policymakers, therefore, is whether linking some elements of the pay scheme of employees to their individual performance, or to the performance of the company, will have a direct and beneficial effect on productivity. Available empirical evidence supports the view that PRP schemes are indeed associated with higher employee productivity and better worker-firm match. The literature has investigated the effect of both individual incentive schemes and group incentive schemes. Individual incentive schemes might involve piece-rate payment and are often referred to as "high-power incentives" [2], [3]. Group incentive schemes can involve teamwork incentives, profit-sharing, and share ownership, and 
are often referred to as "low-power incentives," due to the presence of "free-riding," where less-productive workers will take advantage of being in a larger group and are therefore less easily monitored [4], [5].

Earlier studies from the 1990s tend to show a positive association between PRP schemes and productivity [6]. However, much of this research ignored the fact that firms often change pay schemes along with other changes in work organization practices, which may also affect performance. Additionally, firms that adopt PRP schemes may do so because they are doing well, or because they have "good management" in place that might improve performance with any innovation.

\section{Individual incentive schemes}

Several studies have examined the effect of a change from fixed-pay to piece-rate or other individual incentive schemes related to a firm's productivity. These studies, covering different countries and different time periods, in general report a sizable effect (30-40\%) of individual PRP schemes on average firm productivity. This effect is the combination of the incentive and the type of scheme employed.

One seminal study in this area examined what happened to the productivity of a company operating in the car repair industry (auto windscreens) when fixed hourly rates were replaced by a piece-rate pay regime based on the number of windscreens fitted [3]. The change to a piece-rate pay regime determined a large increase in productivity (44\%), half of which was due to the "incentive effect" (workers being more motivated and putting in more effort) and half to the worker "sorting effect" (e.g. more productive workers joined or stayed with the firm, while the less productive left).

Another important study involving a US shoe company investigated a reversal in an individual incentive pay scheme that shifted from piece-rate pay to time-rate pay. Productivity measured by monthly average shoes produced per day fell by about $6 \%$ with the movement to time rates. However, since piece rates required costly monitoring of output, profits increased when moving to time-rate pay, despite the decline in labor productivity [7].

A different set of studies introduced experimental variation in the mode of compensation in UK fruit-picking farms, randomly allocating workers to different pay-setting regimes and recording the effect on a number of economic outcomes (such as effort, productivity, wages, profits, etc.) [8]. These studies show a sizable increase in productivity (20-50\%), which is the result of a mix of behavioral responses of workers to pay incentives and of managers selecting the more able workers.

Overall these studies suggest that individual incentive schemes, piece rates in particular, induce greater effort than fixed rates. They also induce sorting of more productive workers. The impact on profitability, however, is uncertain due to the higher costs associated with monitoring of output.

\section{Group incentive schemes and financial participation}

Typically, group performance schemes are introduced at the same time a company makes a switch to team-based production, or other organizational or managerial changes. Studies in 
this area generally use panel data at the company level, or personnel data from case studies, in order to compare the effects of the change in pay schemes on firm productivity.

The empirical evidence presented in one review suggests a productivity-enhancing effect of group incentive schemes [1]. One example is the case of a garment plant in the US that shifted from individual piece-rate pay for specific tasks to group incentive pay for each entire garment, while simultaneously introducing autonomous teamworking. Group performance pay resulted in an increase in productivity of about $18 \%$, part of which was due to high-ability workers sorting into team production, and the rest due to greater effort induced by group performance pay.

The introduction of firm-wide schemes in large companies has also been widely investigated, since large companies are more likely to suffer from free-riding problems and low-power incentives. One study examined the productivity effects associated with the introduction of a firm-wide incentive scheme in a large US airline company. The incentive scheme was based on a bonus linked to firm-wide targets. The main findings show that the bonus scheme raised performance (e.g. measured by improvements in on-time departures) as co-worker monitoring within each work group was effective in reducing free-riding [9].

A number of studies investigated the causal effect of PRP on productivity, explicitly accounting for the potential selectivity in the adoption of incentive schemes; i.e. when more profitable firms are more likely to introduce PRP. One study using panel data for a sample of Dutch firms reports a substantial increase in productivity (9\%) in firms adopting PRP schemes, as well as an effect on worker flows [4]. Another study focused on a large sample of metal-mechanical forms in Italy exploiting a reform in the structure of collective bargaining triggered by a social pact, which induced a switch from fixed wages to collective PRP [5]. Results show that an increase in firms' probability of adoption of collective PRP led to productivity gains up to $5 \%$. The effect on productivity is shown to vary substantially by firm size, industry affiliation, and union density. Both the size of the bonus and the design of the scheme-in terms of number and type of parameters used-are also found to be important features for firm productivity.

The impact of share-ownership schemes and employee stock options on performance is more difficult to assess. A number of studies have focused on the US, UK, and Japanese employee stock ownership plan (ESOP) systems. The available evidence shows that the introduction of ESOPs leads to a 3-5\% increase in productivity, but the effect takes several years to show up [1].

The most recent evidence on the operation of share schemes and their impact on firms' performance is a study based on firms that run share schemes (e.g. the so-called "shared capitalism" firms) in the US. Results show that shared capitalism is associated with better firm performance, partly because share schemes complemented other high involvement human resources policies and partly because the diffusion of teamwork facilitated workers' co-monitoring, which reduced free-riding behavior [10].

\section{The diffusion, incidence, and determinants of performance-related pay}

Cross-country evidence on the incidence and growth of PRP shows that these are related to country differences in terms of company size (e.g. often there are mandatory provisions for large firms), regulations in the labor and product markets (e.g. regulation reduces competitive 
pressures to introduce PRP) and the existence of fiscal incentives (e.g. reduced taxation for variable components of pay).

During the 1980s and 1990s, studies for the US report that 5-10\% of employees had some form of incentive pay, with wide differences by industry (ranging from $2 \%$ in the chemical industry to $26 \%$ in the service sector) and occupation (from $2 \%$ in low-skilled blue-collar occupations up to $21 \%$ in sales occupations). By the late 1990 s and 2000 s, the proportion of employees covered by incentive pay schemes increased substantially [1].

Studies for Europe report a wide adoption of PRP schemes only in large companies (i.e. those with more than 200 employees), with nearly one in two (45\%) having some form of sharing schemes, and nearly one-third (31\%) having an employee share-ownership scheme. Comparable figures for employee coverage, however, show lower incidences of $10-12 \%$ for sharing schemes and $2 \%$ for ownership schemes, reflecting the fact that in most firms only a small minority of workers receives incentive pay [1].

Capital market development is also found to be associated with the diffusion of incentive pay. Sharing and ownership schemes are more likely to occur when a larger proportion of companies are listed on the stock exchange or capital markets are otherwise more developed. Figure 1 shows a strong positive correlation between an index of capital market development (e.g. the World Bank, World Development Indicators: "Market capitalization of listed companies (\% of GDP)") and the diffusion of incentive pay [1].

Figure 1. Incidence of incentive pay and market capitalization of listed companies

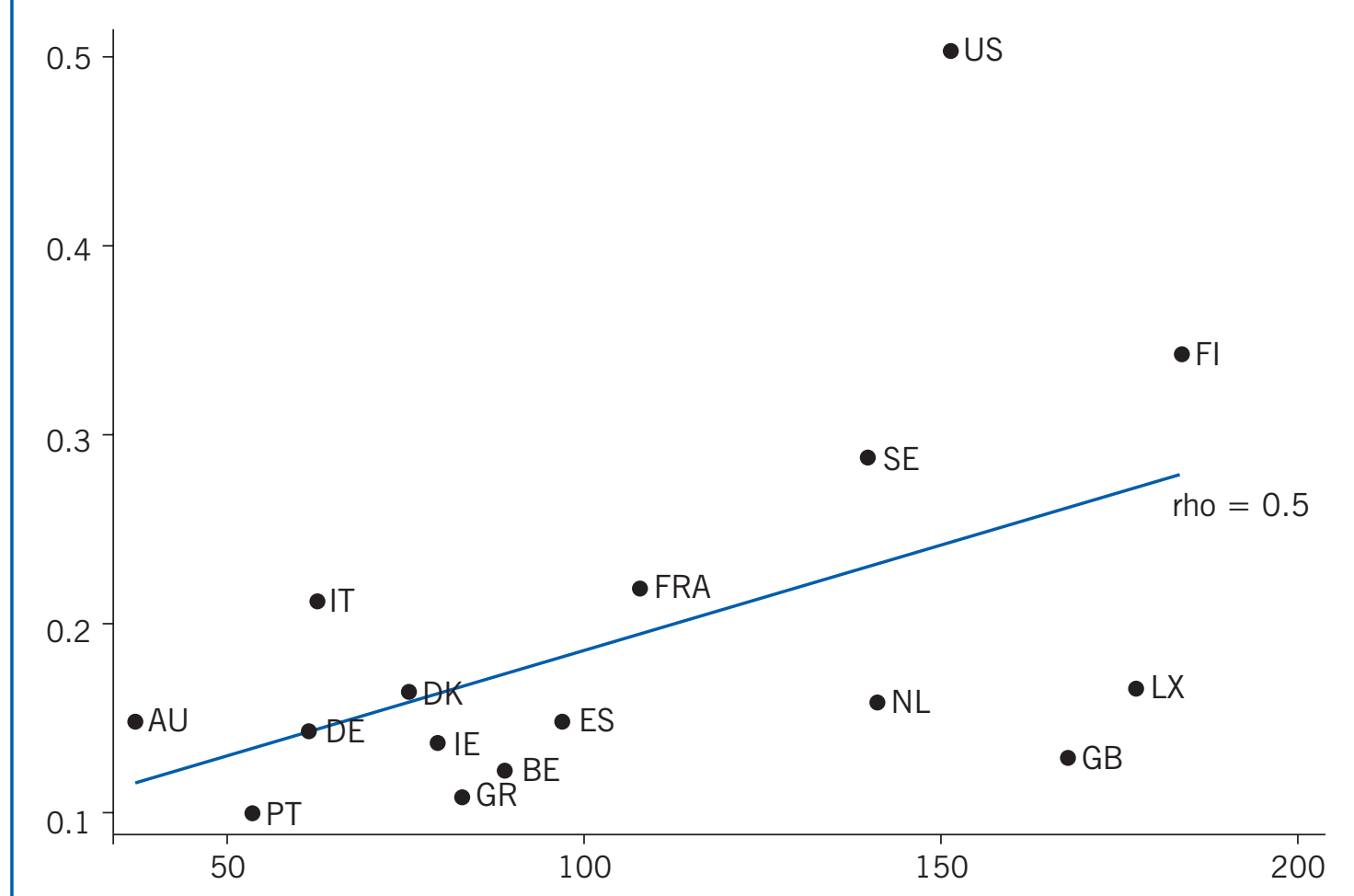

Source: EWCS, GSS data, and World Bank, World Development Indicators: "Market capitalization of listed companies (\% of GDP)"; Boeri, T., C. Lucifora, and K. J. Murphy. Executive Remuneration and Employee Performance-Related Pay. Oxford: Oxford University Press, 2013; p. 164; Figure 6.12. 


\section{Fiscal advantages and other forms of government support}

In a number of countries there are fiscal advantages to the firm and/or the employee, in the form of tax exemptions, tax allowances for investment projects, as well as for schemes meeting given criteria (e.g. schemes that are universal, or deferred schemes).

Profit-sharing and employee share-ownership schemes have been the main forms subsidized by governments since World War II. For example, the US ESOP is a specific type of governmentsubsidized scheme, under which a firm can take out a subsidized bank loan to buy some of its shares for its employees, and the shares (which are initially held in trust), are gradually released to employees. French support for profit-sharing schemes in large firms is another example. In both cases, however, the rationale for government support did not explicitly involve firm performance. Rather, it was a move to increase the involvement of employees in the management of the firm (e.g. "share-owning democracy") and promote savings [10].

\section{Performance-related pay in the public sector}

The diffusion of incentive schemes in the public sector is reported to be much lower compared to the private sector. One explanation may be that incentives in the public sector could simply be "optimally" low, since high-powered incentives (e.g. such as individual PRP) may induce excessive competition, whereas public services require employees' cooperation. Another reason is that it is more difficult to measure output in the public sector: teamwork, multiple objectives, multiple principals, and difference in objectives are among the main features that reduce the benefits of incentive pay.

Finally, it is generally argued that public-sector employees have higher "intrinsic" motivation and are relatively more risk-averse, such that pecuniary incentive and variable pay may be even counter-productive [11]. Across the EU, 5\% of public-sector employees have incentive pay compared with $15 \%$ in the private sector. In the US, the figures are $15 \%$ and $48 \%$ respectively [12].

\section{The unintended effects of performance-related pay}

\section{Intrinsic versus extrinsic motivation}

Some organizational psychologists contest the efficacy of extrinsic incentives, such as pay for performance, as in some settings it may displace workers' intrinsic motivation. While extrinsic motivation refers to motivation that comes from explicit incentives (e.g. pecuniary or future promotions), intrinsic motivation is a personal trait characterizing individual preferences. In other words, providing incentives based on extrinsic motivation may offset an inner willingness to work or perform certain tasks and actually reduce output. The usual example brought forward to highlight some of the unintended effects of PRP is that of non-profit-oriented firms and public-sector workers, where intrinsic motivation is expected to be highest [11].

\section{Pay variability and risk aversion}

An often-neglected feature of PRP schemes is the risk component that is embedded in a contract with variable pay. Assuming that firms are risk-neutral while workers are risk-averse, 
the introduction of a PRP scheme involves a trade-off between efficiency and insurance. In a standard fixed-pay scheme, workers are fully insured and exert low effort, thus reducing efficiency. In a PRP scheme, workers elicit higher effort but also bear part of the risk associated to output variability, because the level of insurance now depends on the ratio of variable to fixed pay (e.g. under piece-rate schemes there is no insurance). In share-ownership schemes, employees own shares of the firm in which they work, hence their income is affected by the firm's performance (as dividends), and their wealth depends on the share price. The risk involved in share fluctuations is added to the employment risk, which in the impossibility of adequate diversification may expose employees to an excessive level of risk with adverse effects on their morale [2].

\section{Multitasking agency problems}

When output or performance are difficult to measure, PRP schemes may have unintended consequences on workers' morale. Measurement problems may arise from teamwork, multitasking, or multiple objectives, in such a way that the benefits of incentive pay may be reduced and firms may become quite conservative in defining pay schemes. A well-known finding in the literature suggests that tasks should be organized according to the expected cost of measuring and rewarding performance. Workers performing easy-to-measure tasks should be paid contingent on performance, while workers assigned to hard-to-measure tasks should receive fixed wages. When a worker has both easy and hard-to-measure tasks, she will concentrate on the easy-to-measure tasks at the expense of the hard-to-measure tasks.

Additionally, in a context where teamwork and employees' cooperation are important, the introduction of high-powered incentives (e.g. such as individual PRP) may induce excessive competition and reduce employees' willingness to cooperate. Empirical evidence from a case study about the introduction of a balanced scorecard (a monitoring tool based on a wide range of information on linked activities) in a large multinational firm showed that due to the complexity and the large number of indicators, the overall effect on performance was negligible, if not negative. Only experienced managers performed better as they were able to effectively allocate effort within the branch [13].

\section{Work intensification and job stress}

While a lot of attention has been paid to the positive effects of incentive pay schemes on employees' effort, motivation, and turnover, relatively little attention has been paid to the possibility that incentive pay may induce employees to over-exert themselves and generate excessive work intensification and psychological stress. Thus, while increased work pressure may or may not improve performance in the short term, it may also have a detrimental effect on employees' long-term performance through its effects on health.

Studies in this area show mixed results, as the effects of work pressure on performance seem to depend on the type of PRP scheme (individual versus group incentive schemes), workers' position in the occupational hierarchy (managerial versus non-managerial occupations) and the size of the firm. One study using employer-employee data for a large sample of French manufacturing firms finds evidence consistent with the above hypotheses, namely that individual bonuses in managerial occupations are likely to exert high work pressure, with potential adverse effects on firms' long-term performance [1]. 


\section{LIMITATIONS AND GAPS}

A major drawback of the existing empirical studies is the uncertainty regarding the external validity of the findings with respect to other firms, industries, or to other countries. The empirical strategy adopted to overcome some of the estimation bias typically relies on information drawn from case studies and field experiments that are not easily generalizable. In most of the studies reviewed in this contribution, the effect of the introduction of an incentive scheme in one branch of a company, or in the whole company itself, is compared to that of other branches or companies that are unaffected by the change. While results are important in shedding light on the mechanisms through which pay incentives influence employees' behavior and firms' performance, some care should be used in drawing general conclusions or expecting the same effects to occur across time, place, and environment. Moreover, firms that change their mode of pay generally do so because the firm is not efficient in terms of performance or profitability, such that other changes in work organization or management style are often introduced along with incentive pay, which makes it difficult to identify a causal effect on output.

Also, it should be remembered that explicit incentives, such as PRP schemes, are just one aspect of the overall system of incentives that firms can use to select, retain, and motivate employees. Other incentive mechanisms include implicit long-term incentives, such as competition processes for promotion, which is determined by the corporate structure and hiring policy.

Another limitation is related to firm heterogeneity, or differences across firms. In general, what works in one firm may or may not work in another firm depending on managerial ability, implementation of incentive schemes, and other features of the firm's environment. The evidence presented here highlights some general findings that are common to a number of studies in different countries, allowing policymakers to draw a general view about the sign and magnitude of the expected impact of the introduction of PRP schemes on firms' performance. However, it does not suggest that a specific policy will certainly work in a given firm or in a given industry.

\section{SUMMARY AND POLICY ADVICE}

PRP schemes are an effective way of increasing performance both at the level of the company or firm, as well as at the macro level, provided that the type and design of the schemes are appropriate. Compensation packages with a PRP component are associated, at the company level, with higher worker effort, a better matching between workers and firms, and lower turnover for the more productive workers in the firm. At the macro level the diffusion of incentive pay schemes is associated with higher productivity, more wage flexibility, and better resilience to economic shocks.

In particular, individual pay schemes generally exhibit larger increases in productivity, due to the combined effects of higher individual effort, as well as a more favorable composition of high-productive workers.

The effects of group incentive schemes and financial participation are also positive but smaller, due to free-riding and the low power of group incentives. This has been reported to be more relevant in larger-sized firms.

Overall, a general finding, common to most studies, is that companies with well-designed PRP schemes have better (or no worse) economic outcomes than other firms. 
While it is true that an increasing proportion of firms has adopted PRP schemes in recent decades, on the basis of the empirical evidence, it is somewhat puzzling that incentive pay is not more widely diffused across firms in most countries. Part of the explanation may lie in the uncertainty that is associated with changes in work organization practices and pay regimes: what works in one setting may not work in another, due to the difference of the effects across firms and work environments. Also, there might be resistance of (risk-averse) workers in accepting variations in income, such that workers (and their unions) prefer to negotiate compensation packages that are not linked to performance.

The institutional context also contributes to the differences in the effects on performance: in some countries PRP, or financial participation, is mandatory (e.g. in large firms). In other countries there are no specific measures adopted for firms with PRP schemes in place. Thus the question of whether a government should, or should not, intervene in private-sector firms' pay setting is necessarily related to the existence of market failures or inefficient outcomes.

The evidence reviewed in this contribution suggests that a case for policy intervention might be that of facilitating the introduction of PRP schemes in some (young and small) firms where the implementation of such schemes may be too difficult and costly, so even if productivity gains are there, the effect on profitability might be uncertain. Then moving them in a more productive direction can justify a policy to encourage greater incentive pay or financial participation, ranging from programs to educate firms about best-practice techniques and how to implement them, to using tax breaks or subsidies to induce firms to undertake these initiatives or, even, to making such programs mandatory.

However, particular care should be used in government intervention "across the board" to support the introduction and diffusion of PRP schemes with subsidies or tax breaks, since this may benefit firms that already have them or will have introduced them anyhow. Also, the existence of government incentives for the introduction of PRP schemes may induce firms to change their pay policies simply in order to gain tax advantages without changing how they actually operate and without any productivity gain.

This variance suggests that the case for government intervention, in terms of what type of measures should be envisaged to induce firms to adopt incentive pay schemes and whether such schemes should be subsidized, is to be evaluated with care, as there can be potential "deadweight" losses, or economic inefficiencies, involved.

\section{Acknowledgments}

The author thanks an anonymous referee and the IZA World of Labor editors for helpful suggestions on earlier drafts. Previous work jointly authored with A. Bryson, R. Freeman, M. Pellizzari, and V. Pérotin contains a larger number of background references for the material presented here and has been used intensively in all major parts of this article [1].

\section{Competing interests}

The IZA World of Labor project is committed to the IZA Guiding Principles of Research Integrity.

The author declares to have observed these principles.

(C) Claudio Lucifora 


\section{REFERENCES}

\section{Further reading}

Boeri, T., C. Lucifora, and K. J. Murphy. Executive Remuneration and Employee Performance-Related Pay. Oxford: Oxford University Press, 2013.

Kessler, I., and J. Purcell, "Performance related pay: Objectives and application." Human Resource Management Journal 2:3 (1992): 16-33.

\section{Key references}

[1] Bryson, A., R. Freeman, C. Lucifora, M. Pellizzari, and V. Pérotin. "Paying for performance: Incentive pay schemes and employees' financial participation." In: Boeri, T., C. Lucifora, and K. J. Murphy (eds). Executive Remuneration and Employee Performance-Related Pay. Oxford: Oxford University Press, 2013.

[2] Prendergast, C. "The provision of incentives in firms." Journal of Economic Literature 37:1 (1999): 7-63.

[3] Lazear, E. "Performance pay and productivity." American Economic Review 90:5 (2000): 13461361.

[4] Gielen, A. C., M. J. M. Kerkhofs, and J. C. van Ours. "How performance related pay affects productivity and employment." Journal of Population Economics 23:1 (2010): 291-301.

[5] Lucifora, C., and F. Origo. "Performance-related pay and firm productivity: Evidence from a reform in the structure of collective bargaining." Industrial and Labor Relations Review 68:3 (2015): 606-632.

[6] Cable, J. R., and N. Wilson. "Profit sharing and productivity: Some further evidence." The Economic Journal 100:401 (1990): 550-555.

[7] Freeman, R. B., and M. M. Kleiner. "The last American shoe manufacturers: Decreasing productivity and increasing profits in the shift from piece rates to continuous flow production." Industrial Relations 44:2 (2005): 307-330.

[8] Bandiera, O., I. Barankay, and I. Rasul. "Incentives for managers and inequality among workers: Evidence from a firm-level experiment." The Quarterly Journal of Economics 122:2 (2007): 729-773.

[9] Knez, M., and D. Simester. "Firm-wide incentives and mutual monitoring at Continental Airlines." Journal of Labor Economics 19:4 (2001): 743-772.

[10] Kruse, D. L., R. B. Freeman, and J. R. Blasi. Shared Capitalism at Work: Employee Ownership, Profit and Gain Sharing and Broad-based Stock Options. Chicago: University of Chicago Press, 2010.

[11] Prendergast, C. "Intrinsic motivation and incentives." American Economic Review 98:2 (2008): 201-205.

[12] Burgess, S., and M. Ratto. "The role of incentives in the public sector: Issues and evidence." Oxford Review of Economic Policy 19:2 (2003): 285-300.

[13] Griffith, R., and A. Neely. "Performance pay and managerial experience in multitask teams: Evidence from within a firm.” Journal of Labor Economics 27:1 (2009): 49-82.

\section{The full reference list for this article is available from the IZA World of Labor website} (http://wol.iza.org/articles/performance-related-pay-and-labor-productivity). 